\title{
Treatment-completion rates with olanzapine long-acting injection versus risperidone long-acting injection in a I2-month, open-label treatment of schizophrenia: indirect, exploratory comparisons
}

This article was published in the following Dove Press journal:

International Journal of General Medicine

3 May 2012

Number of times this article has been viewed

\author{
Haya Ascher-Svanum' \\ William S Montgomery ${ }^{2}$ \\ David P McDonnell ${ }^{3}$ \\ Kristina A Coleman ${ }^{4}$ \\ Peter D Feldman' \\ 'Lilly Research Laboratories, Eli Lilly \\ and Company, Indianapolis, IN, USA; \\ ${ }^{2}$ Eli Lilly Australia Pty Ltd, West Ryde, \\ New South Wales, Australia; ${ }^{3}$ Eli Lilly \\ and Company, Cork, Ireland; \\ ${ }^{4}$ Optumlnsight, Lilyfield, New South \\ Wales, Australia
}

Background: Little is known about the comparative effectiveness of atypical antipsychotics in long-acting injection formulation. Due to the absence of head-to-head studies comparing olanzapine long-acting injection and risperidone long-acting injection, this study was intended to make exploratory, indirect, cross-study comparisons between the long-acting formulations of these two atypical antipsychotics in their effectiveness in treating patients with schizophrenia.

Methods: Indirect, cross-study comparisons between olanzapine long-acting injection and risperidone long-acting injection used 12-month treatment-completion rates, because discontinuation of an antipsychotic for any cause is a recognized proxy measure of the medication's effectiveness in treating schizophrenia. Following a systematic review of the literature, two indirect comparisons were conducted using open-label, single-cohort studies in which subjects were stabilized on an antipsychotic medication before depot initiation. The first analysis compared olanzapine long-acting injection (one study) with pooled data from nine identified risperidone long-acting injection studies. The second analysis was a "sensitivity analysis," using only the most similar studies, one for olanzapine long-acting injection and one for risperidone long-acting injection, which shared near-identical study designs and involved study cohorts with near-identical patient characteristics. Pearson Chi-square tests assessed group differences on treatment-completion rates.

Results: Comparison of olanzapine long-acting injection data (931 patients) with the pooled data from the nine risperidone long-acting injection studies (3950 patients) provided almost identical 12 -month treatment-completion rates $(72.7 \%$ versus $72.4 \% ; P=0.87)$. When the two most similar studies were compared, the 12-month completion rate for olanzapine long-acting injection was significantly higher than for risperidone long-acting injection $(81.3 \%$ versus $47.0 \% ; P<0.001)$. However, any conclusions drawn from this comparison may be limited by differences in the studies' geographic catchment areas.

Conclusion: Using treatment-completion rates as a proxy measure of medication effectiveness, olanzapine long-acting injection did not differ significantly from risperidone long-acting injection when including all eligible studies. However, the findings of this exploratory analysis should be interpreted with caution, considering the methodological limitations of these indirect, cross-study comparisons.

Keywords: antipsychotic drugs, intramuscular injection, olanzapine, risperidone, schizophrenia
Correspondence: Haya Ascher-Svanum Lilly Research Laboratories, Eli Lilly and Company, Lilly Corporate Center, Drop Code I730, Indianapolis, IN 46285, USA Tel +I $31727787 \mid 3$

Fax +I 3174332997

Email haya@lilly.com 


\section{Introduction}

Nonadherence to medication is a major risk factor contributing to relapse and hospitalization among patients with schizophrenia. ${ }^{1,2}$ Treatment with antipsychotics in long-acting injection formulations (depot) is recognized as a safe and effective strategy for improving medication adherence ${ }^{3,4}$ and appears to benefit patients with schizophrenia who are nonadherent to medications. ${ }^{5}$ Currently, several atypical antipsychotics are available in long-acting "depot" injections: a microsphere formulation of risperidone ${ }^{6}$ (risperidone long-acting injection), a pamoate salt of olanzapine ${ }^{7}$ (olanzapine long-acting injection), and a palmitate ester of paliperidone, ${ }^{8}$ the major metabolite of risperidone. Still other long-acting injectable formulations are in development, such as a cholesterol-based, implantable preparation of aripiprazole. ${ }^{9}$ The earliest of these formulations to receive marketing approval in the United States, risperidone long-acting injection and olanzapine long-acting injection, have been available for several years. However, the comparative effectiveness of these two medications is unclear, as they have not been compared yet in any head-to-head study. The aim of this analysis was to compare the effectiveness of olanzapine long-acting injection and risperidone long-acting injection in the long-term, open-label treatment of patients with schizophrenia, using 12-month treatment-completion rates as a proxy measure of treatment effectiveness. Treatment-completion rate is considered a proxy measure of treatment effectiveness, as it reflects both patients' and physicians' judgments of the efficacy, safety, and tolerability of a medication. ${ }^{10,11}$ In previous head-to-head research of olanzapine and risperidone in standard oral tablet formulation in the treatment of schizophrenia, olanzapinetreated patients were found to stay on therapy significantly longer and have significantly lower treatment-discontinuation rates compared with risperidone-treated patients. ${ }^{10-22}$ It is currently unknown whether findings from studies of the oral formulations of olanzapine and risperidone would extend to their depot formulations, as there are no head-to-head studies comparing the long-acting injectable formulations of these two medications.

\section{Materials and methods}

Data used in this analysis were identified via a systematic search of the published and unpublished literature. A search of the Embase ${ }^{\circledR}$ (Elsevier BV, Amsterdam, The Netherlands) and Medline $^{\circledR}$ (National Library of Medicine, National Institutes of Health, Bethesda, MD) databases was conducted to identify relevant studies of olanzapine long-acting injection and risperidone long-acting injection using the following search terms: "olanzapine pamoate depot", "olanzapine depot", "olanzapine long-acting", or "long-acting olanzapine", "Risperdal Consta", "risperidone depot", "risperidone long-acting", and "long-acting risperidone". In addition, potentially relevant olanzapine long-acting injection trials were identified via a search of the Eli Lilly internal database, and from the reference lists of identified studies and reviews.

Studies were eligible for inclusion in the analysis if they met the following criteria: an open-label design (ie, patients and investigators were aware of what treatment they were assigned to); patients received either olanzapine long-acting injection or risperidone long-acting injection (ie, only a "single cohort" was involved); age $\geq 18$ years; inclusion of patients with a diagnosis of schizophrenia or a related disorder (for example, schizoaffective disorder); and availability of data reporting the proportion of patients completing at least 12 months of treatment with olanzapine long-acting injection or risperidone longacting injection. In addition, studies had to include patients who were symptomatically stable at baseline. The latter criterion was included to increase comparability between the olanzapine long-acting injection and risperidone long-acting injection studies, because there has been only one olanzapine long-acting injection open-label, single-cohort study, F1DMC-HGKB (referred to hereafter simply as HGKB), ${ }^{23}$ and this study included patients who were stable at baseline.

Data regarding study and patient characteristics, as well as 12-month completion rates, were extracted from the included studies. Two comparisons of 12-month completion rates were made. The first analysis compared data from the olanzapine long-acting injection study (HGKB) and all identified risperidone long-acting injection studies that met the inclusion criteria. The second analysis was conducted as a form of sensitivity analysis, comparing olanzapine long-acting injection data with that from the risperidone long-acting injection study that was most similar in design and patient characteristics. Group comparisons of 12-month treatment-completion rates were conducted using Fisher's exact test.

\section{Results}

The literature search resulted in the identification of 10 studies with 4901 patients (olanzapine long-acting injection, $\mathrm{n}=931$; risperidone long-acting injection, $\mathrm{n}=3970$; Table 1). Of the 10 studies, one was presented as an unpublished study report ${ }^{23}$ (F1D-MC-HGKB) providing effectiveness data on olanzapine long-acting injection and in two published articles, ${ }^{24,25}$ and nine publications provided effectiveness data on risperidone long-acting injection. ${ }^{26-34}$ The HGKB olanzapine long-acting injection study ${ }^{23,25}$ was 


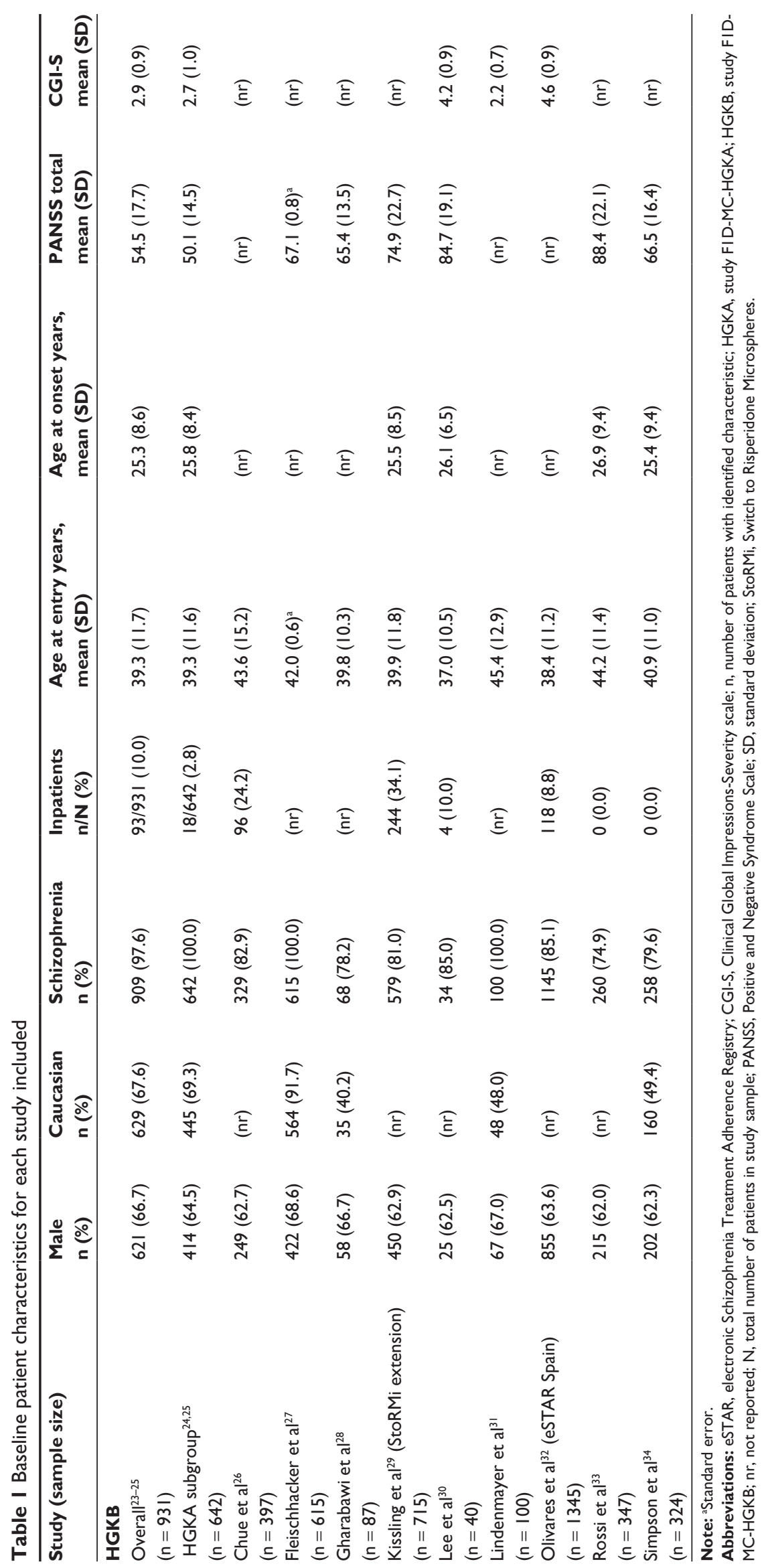


an open-label, single-cohort extension study that enrolled patients from 128 sites in 25 countries in North and South America, Europe, Asia, Africa, the Middle East, and Australia who completed one of three previous clinical trials ("feeder studies"). The three trials included an 8-week randomized, double-blind, placebo-controlled inpatient study ${ }^{35}$ of olanzapine long-acting injection (F1D-MC-HGJZ), a maintenance study $^{36,37}$ in which patients stabilized on oral olanzapine for 4-8 weeks were randomly assigned to oral olanzapine or olanzapine long-acting injection for 24 weeks of doubleblind treatment (F1D-MC-HGKA), and a pharmacokinetic study $^{38}$ of olanzapine long-acting injection (F1D-EW-LOBS). The 12-month treatment-completion rate on olanzapine long-acting injection was calculated twice, for two populations in the HGKB study: all HGKB patients, regardless of which feeder study they came from, ${ }^{23-25}$ and only patients who entered HGKB after completing HGKA, a randomized, controlled trial comparing olanzapine long-acting injection with oral olanzapine in patients with schizophrenia who were first stabilized on oral olanzapine (data on file, Eli Lilly and Company and/or one of its subsidiaries ${ }^{31,36}$ ).

The nine risperidone long-acting injection studies, with one exception, were single-cohort, open-label studies involving male or female adult (aged $\geq 18$ years) patients. The one study that was an exception to the "single cohort" inclusion criterion $^{34}$ had randomized patient treatment assignments to one of two dosing regimens of open-label risperidone longacting injection, and as such, was considered a single treatment cohort of risperidone long-acting injection. Of special interest was the study by Lindenmayer et al, ${ }^{31}$ which reported 12 -month treatment-completion rates for two cohorts of patients being treated with open-label, flexible-dose risperidone long-acting injection in an extension study of two previous "feeder" studies: study A, which included patients from 41 sites in the United States who had either completed or been withdrawn from a 12-week, double-blind, randomized, controlled trial of inpatients comparing risperidone long-acting injection and placebo, ${ }^{39}$ and study B, which included patients from 28 sites in the United States who had completed a 12-week, openlabel outpatient study of risperidone long-acting injection. ${ }^{40}$ Unlike study B, study A did not include all patients who had completed the feeder study, and it is unclear whether study A participants were stable when enrolled in the extension study by Lindenmayer et al. ${ }^{31}$ The 12-month treatment-completion rate for patients in study A was reported in the text ${ }^{39}$ to be $55 \%$. However, other information reported for patient disposition (as represented in a figure of the published report of study A) indicated a 12-month completion rate of $50 \%$.
Baseline characteristics of participants in each of the 10 included studies are presented in Table 1 . The majority of patients were male ( $62 \%$ to $69 \%$ ) and had a diagnosis of schizophrenia (75\% to $100 \%$ ). Racial origin varied widely among the studies reporting racial origin, with Caucasians constituting as few as $40.2 \%$ of the patients in the Gharabawi et al study ${ }^{28}$ and as many as $92 \%$ of the patients in the study by Fleischhacker et al. ${ }^{27}$ Five studies did not report racial origin. Study participants also differed with regard to their baseline symptom severity, with mean baseline total scores on the Positive and Negative Syndrome Scale ${ }^{41}$ (PANSS) ranging from 54.5 (mildly ill $^{42}$ ) in the HGKB study to 88.4 (moderately to markedly $\mathrm{ill}^{42}$ ) in the study by Rossi et al, ${ }^{33}$ while baseline Clinical Global Impressions-Severity scale ${ }^{43}$ (CGI-S) scores ranged from 2.2 (borderline mentally ill to mildly ill) in study B of the Lindenmayer study ${ }^{31}$ to 4.6 (moderately to markedly ill) in the Olivares electronic Schizophrenia Treatment Adherence Registry (e-STAR) study. ${ }^{32}$ Baseline PANSS scores were not provided for three of the 10 studies, and baseline CGI-S scores were not provided for six of the studies.

In the HGKB study, $90 \%$ of all patients treated with olanzapine long-acting injection were outpatients at baseline, and $10 \%$ were inpatients. ${ }^{24}$ In the HGKA subgroup of the HGKB study, ${ }^{25}$ 97\% were outpatients at baseline, while 3\% were inpatients (data on file). Information about outpatient and inpatient status at baseline was not reported in all risperidone long-acting injection studies. Studies reporting status indicated that the proportion of inpatients ranged from $0 \%$ in the studies by Rossi et $\mathrm{al}^{33}$ and Simpson et $\mathrm{al}^{34}$ to $34 \%$ in the Switch to Risperidone Microspheres (StoRMi) extension study by Kissling et al. ${ }^{29}$

As presented in Table 2, a comparison of data from all 10 studies (analysis 1) showed nearly identical 12-month treatment-completion rates for patients treated with olanzapine long-acting injection or risperidone long-acting injection (72.7\% versus $72.4 \%$, respectively; $P=0.87$ ). Completion rates for risperidone long-acting injection ranged from $47.0 \%$ for study B conducted by Lindenmayer et al in the United States $^{31}$ to $86.1 \%$ for the Olivares eSTAR study conducted in Spain. ${ }^{32}$

Due to the disparity between the included studies in their designs and patient baseline characteristics, a second analysis (analysis 2) was conducted between the two most similar studies as a form of sensitivity analysis. For olanzapine long-acting injection, this was the HGKA cohort from the HGKB $\operatorname{study}^{25}$ ( $\mathrm{n}=642$; data on file), and for risperidone long-acting injection, it was the study B cohort $(n=100)$ from the study by Lindenmayer et al. ${ }^{31}$ There were 
Table 2 Twelve-month completion rates for olanzapine longacting injectable or risperidone long-acting injectable (analysis I)

\begin{tabular}{|c|c|c|c|}
\hline Study & $\begin{array}{l}\text { Baseline } \\
\text { medication(s) }\end{array}$ & $\begin{array}{l}\text { OLAI } \\
\text { n/N (\%) }\end{array}$ & $\begin{array}{l}\text { RLAl } \\
\text { n/N (\%) }\end{array}$ \\
\hline $\mathrm{HGKB}^{23-25}$ & OLAI & $\begin{array}{l}677 / 931 \\
(72.7)\end{array}$ & \\
\hline Chue et $\mathrm{al}^{26}$ & Any antipsychotic & & $281 / 397(70.7)$ \\
\hline Fleischhacker et $\mathrm{a}^{27}$ & Any antipsychotic & & $400 / 615(65.0)$ \\
\hline Gharabawi et $\mathrm{al}^{28}$ & Oral risperidone & & $33 / 67^{\mathrm{b}}(49.3)$ \\
\hline $\begin{array}{l}\text { Kissling et } \mathrm{al}^{29} \\
\text { (StoRMi } \\
\text { extension) }\end{array}$ & RLAI & & $508 / 7 / 5$ (7I.0) \\
\hline Lee et $\mathrm{al}^{30}$ & Oral antipsychotic & & $25 / 40(62.5)$ \\
\hline $\begin{array}{l}\text { Lindenmayer et } \mathrm{al}^{31} \\
\text { (study B) }\end{array}$ & RLAI & & $47 / 100(47.0)$ \\
\hline $\begin{array}{l}\text { Olivares et al } \\
\text { (eSTAR Spain) }\end{array}$ & Any antipsychotic & & II I58/I345 (86.I) \\
\hline Rossi et $\mathrm{al}^{33}$ & Any antipsychotic & & $243 / 347(70.0)$ \\
\hline Simpson et $\mathrm{al}^{34}$ & Any antipsychotic & & I66/324 (5I.2) \\
\hline $\begin{array}{l}\text { Overall I2-month } \\
\text { completion rate }\end{array}$ & & $\begin{array}{l}677 / 931 \\
(72.7)\end{array}$ & $286 I / 3950(72.4)$ \\
\hline
\end{tabular}

Notes: ${ }^{a}=0.87$, olanzapine-LAl versus pooled nine studies of risperidone-LAl, per Pearson Chi-square test; bintent-to-treat population only.

Abbreviations: eSTAR, electronic Schizophrenia Treatment Adherence Registry; $n$ number of patients completing 12 months of treatment; $\mathrm{N}$, total number of patients treated; HGKB, study FID-MC-HGKB; OLAI, olanzapine long-acting injectable; RLAI risperidone long-acting injectable; StoRMi, Switch to Risperidone Microspheres.

notable similarities between the two treatment groups that were compared in analysis 2 :

- Both studies enrolled patients who had completed a previous "feeder" study of the corresponding depot medication and then continued into an extension period. These patients were likely similarly satisfied with their favorable response to treatment and thus willing to continue into the extension phase.

- Both studies included a single cohort of patients with schizophrenia.

- Both studies were open label, with flexible dosing of the medication.

- Both studies included chronically ill but stabilized patients with schizophrenia.

- Both studies included patients who were mildly ill, per mean PANSS total score or CGI scores.

- Both studies used identical prespecified inclusion criteria for baseline PANSS Positive scores (a score $\geq 4$ on each of the following four PANSS positive items: conceptual disorganization, hallucinatory behaviors, suspiciousness, and unusual thought content).

- Both studies used a lead-in period of at least 4 weeks on the corresponding oral formulation prior to switching to the depot formulation.

- Participants in both studies had a similar mean age at study entry.
- Participants in both studies had a similar mean age at illness onset.

- Participants in both studies had a similar proportion of males and females.

Importantly, these patient characteristics (age at study entry, age at illness onset, and sex) have been previously found to be significant predictors of discontinuation on antipsychotic medications in the long-term treatment of patients with schizophrenia. ${ }^{44-50}$ However, the two comparison groups did differ in one important characteristic: geographic catchment area. Patients in the HGKA entry cohort of the olanzapine long-acting injection study represented 25 countries around the globe, whereas patients from the study B group of the risperidone long-acting injection trial were exclusively from the United States. The results of analysis 2 (Table 3) showed significantly higher 12-month treatment-completion rates for the HGKA cohort of the olanzapine long-acting injection trial compared with the study B group of the risperidone long-acting injection study ( $81.3 \%$ versus $47.0 \%$, respectively; $P<0.001)$. It is noteworthy that, for study $\mathrm{B}$, Lindenmayer et $\mathrm{al}^{31}$ reported two different treatment-completion rates, $52 \%$ in the text and $47 \%$ in a figure in the report; the correct rate is $47 \%$, per personal communication from the principal author.

\section{Discussion}

This exploratory analysis made an indirect comparison between olanzapine long-acting injection and risperidone long-acting injection for 12-month treatment-completion rates using open-label, flexible-dose, single-cohort, prospective, observational studies conducted in the usual care of patients with schizophrenia. However, the findings from indirect crossstudy comparisons are susceptible to selection bias and other confounding variables. To help minimize potential bias, we conducted two separate analyses. The first analysis used all

Table 3 Twelve-month completion rates for olanzapine longacting injectable or risperidone long-acting injectable (analysis 2)

\begin{tabular}{llll}
\hline Study & $\begin{array}{l}\text { Baseline } \\
\text { medication(s) }\end{array}$ & $\begin{array}{l}\text { OLAl } \\
\mathbf{n} / \mathbf{N}(\%)\end{array}$ & $\begin{array}{l}\text { RLAl } \\
\mathbf{n} / \mathbf{N} \text { (\%) }\end{array}$ \\
\hline $\begin{array}{l}\text { HGKB } \\
\text { (HG,25 }\end{array}$ & OLAl & $522 / 642$ & \\
$\begin{array}{l}\text { file, Eli Lilly and Company } \\
\text { and/or one of its subsidiaries) }\end{array}$ & & $(81.3)$ & \\
$\begin{array}{l}\text { Lindenmayer et al }{ }^{31} \\
\text { (study B) }\end{array}$ & RLAl & & \\
$\begin{array}{l}\text { Overall I2-month } \\
\text { completion rate }\end{array}$ & & & $47 / 100$ \\
\hline
\end{tabular}

Notes: ${ }^{p}<<0.00$, olanzapine-LAl versus risperidone-LAl, per Pearson Chi-square test. Abbreviations: HGKA, study FID-MC-HGKA; HGKB, study FID-MC-HGKB; $\mathrm{n}$, number of patients completing 12 months of treatment; $\mathrm{N}$, total number of patients treated; OLAl, olanzapine long-acting injectable; RLAl, risperidone longacting injectable. 
eligible studies reporting 12-month treatment-completion rates and found no significant difference between the two depot drugs on treatment-completion rates. However, because medication discontinuation rates tend to be influenced by study design, country of study sites, study burden, and patients' clinical and demographic characteristics, we also attempted to conduct an additional sensitivity analysis by selecting the risperidone long-acting injection study most similar to the single olanzapine long-acting injection study that was available. This was done due to the marked heterogeneity among the nine available risperidone long-acting injection studies and the need to compare "like with like." The second analysis, which compared results from two studies that were most similar in both their methodology and patient characteristics, found a significantly higher treatment-completion rate for olanzapine long-acting injection compared with risperidone long-acting injection. Results from the second analysis are consistent with those from head-to-head comparative studies of oral olanzapine and risperidone, ${ }^{10-22}$ as well as the results of two other recent and similarly designed studies in the treatment of patients in the United States with schizophrenia. ${ }^{51,52}$ One study ${ }^{52}$ was a randomized, open-label, 2-year study that compared risperidone long-acting injection and oral atypical antipsychotics and reported a high rate of discontinuation (approximately $80 \%$ ) of risperidone long-acting injection for any cause over the 2-year study. The other study ${ }^{51}$ was also a randomized, open-label, 2-year study comparing olanzapine long-acting injection and oral olanzapine, and that study found a relatively lower 2-year discontinuation rate (54.9\%) for any cause on olanzapine longacting injection. However, it is notable that the "most similar" risperidone long-acting injection study used in our second analysis reported a considerably lower treatment-completion rate compared with the other eight risperidone long-acting injection studies. $27,29,30,32,33,53-55$ Moreover, the two studies in analysis 2 differed with respect to their catchment areas, in that the risperidone long-acting injection study B was conducted exclusively in the United States, while the olanzapine longacting injection study was conducted more globally, outside the United States. This may account in large part for the observed disparity in discontinuation rates, because regional differences may lead to differences in study discontinuation rates. ${ }^{56} \mathrm{~A}$ recent paper about a 2-year, single-cohort, openlabel study ${ }^{56}$ of risperidone long-acting injection found the 2-year treatment-completion rates for risperidone long-acting injection to differ markedly among the four countries studied, ranging from $39.3 \%$ in the United States to $62.7 \%$ in Spain. The authors noted that, "variation in discontinuation among the four countries may be due to differences in access to treatment, social support (for example, in patients who live alone), and cost (for example in Spain, RLAT [risperidone long-acting injection] is free to most patients)." This information strongly suggests that the present exploratory comparison would require more definitive proof in the form of a direct, head-to-head comparison under essentially identical study conditions and in the same geography/country to clarify the validity of the current findings.

The current analyses are the first to compare the effectiveness of olanzapine long-acting injection and risperidone long-acting injection side by side and are preliminary and exploratory in nature. Therefore, there is a need to interpret the findings cautiously in the context of their limitations. As noted previously, these analyses were carried out using data from open-label, single-cohort studies, which are susceptible to selection bias and other confounding variables, including the country or countries where the study was conducted. Moreover, there is an imbalance in study representation, with just a single olanzapine long-acting injection study being compared with multiple risperidone long-acting injection studies, the latter being associated with a greater pooled variation in the total patient sample. While every effort was made in our study to ensure comparability of the data used by comparing the two studies most similar in study design and patient baseline characteristics, the differences between olanzapine long-acting injection and risperidone long-acting injection in the 12-month treatment-completion rates could have been an artifact due to differences in the studies' geographies, which often reflect differences in health care practices, social supports, and medication costs. Therefore, the current findings should be interpreted cautiously with these limitations in mind. There is a clear need for comparative head-to-head studies of olanzapine long-acting injection and risperidone long-acting injection in the long-term treatment of patients with schizophrenia, to help accurately delineate the comparative effectiveness of these two atypical antipsychotics in depot formulations.

\section{Disclosure}

HA-S, WSM, DPM, and PDF are employees of, and minor shareholders in, Eli Lilly and Company. KAC is an employee of OptumInsight.

\section{References}

1. Law MR, Soumerai SB, Ross-Degnan D, Adams AS. A longitudinal study of medication nonadherence and hospitalization risk in schizophrenia. J Clin Psychiatry. 2008;69(1):47-53.

2. Valenstein M, Ganoczy D, McCarthy JF, Myra Kim H, Lee TA, Blow FC. Antipsychotic adherence over time among patients receiving treatment for schizophrenia: a retrospective review. J Clin Psychiatry. 2006; 67(10):1542-1550. 
3. Kane JM. Strategies for improving compliance in treatment of schizophrenia by using a long-acting formulation of an antipsychotic: clinical studies. J Clin Psychiatry. 2003;64 Suppl 16:34-40.

4. Marder SR. Overview of partial compliance. J Clin Psychiatry. 2003; 64 Suppl 16:3-9.

5. McEvoy JP. Risks versus benefits of different types of long-acting injectable antipsychotics. $J$ Clin Psychiatry. 2006;67 Suppl 5:15-18.

6. Rainer MK. Risperidone long-acting injection: a review of its long term safety and efficacy. Neuropsychiatr Dis Treat. 2008;4(5): 919-927.

7. Naber D. Olanzapine pamoate for the treatment of schizophrenia. Expert Opin Pharmacother. 2011;12(4):627-633.

8. Pandina GJ, Lindenmayer JP, Lull J, et al. A randomized, placebocontrolled study to assess the efficacy and safety of 3 doses of paliperidone palmitate in adults with acutely exacerbated schizophrenia. J Clin Psychopharmacol. 2010;30(3):235-244.

9. Nahata T, Saini TR. Formulation optimization of long-acting depot injection of aripiprazole by using D-optimal mixture design. PDA J Pharm Sci Technol. 2009;63(2):113-122.

10. Kahn RS, Fleischhacker WW, Boter H, et al. Effectiveness of antipsychotic drugs in first-episode schizophrenia and schizophreniform disorder: an open randomised clinical trial. Lancet. 2008;371(9618):1085-1097.

11. Lieberman JA, Stroup TS, McEvoy JP, et al. Effectiveness of antipsychotic drugs in patients with chronic schizophrenia. $N$ Engl J Med. 2005;353(12):1209-1223.

12. Ascher-Svanum H, Zhu B, Faries DE, Lacro JP, Dolder CR, Peng X. Adherence and persistence to typical and atypical antipsychotics in the naturalistic treatment of patients with schizophrenia. Patient Prefer Adherence. 2008;2:67-77.

13. Beasley CM Jr, Stauffer VL, Liu-Seifert H, Taylor CC, Dunayevich E, Davis JM. All-cause treatment discontinuation in schizophrenia during treatment with olanzapine relative to other antipsychotics. An integrated analysis. J Clin Psychopharmacol. 2007;27(3): 252-258.

14. Bitter I, Treuer T, Dyachkova Y, Martenyi F, McBride M, Ungvari GS. Antipsychotic prescription patterns in outpatient settings: 24-month results from the Intercontinental Schizophrenia Outpatient Health Outcomes (IC-SOHO) study. Eur Neuropsychopharmacol. 2008;18(3): 170-180.

15. Cooper D, Moisan J, Gaudet M, Abdous B, Gregoire JP. Ambulatory use of olanzapine and risperidone: a population-based study on persistence and the use of concomitant therapy in the treatment of schizophrenia. Can J Psychiatry. 2005;50(14):901-908.

16. Dossenbach M, Erol A, el Mahfoud Kessaci M, et al. Effectiveness of antipsychotic treatments for schizophrenia: interim 6-month analysis from a prospective observational study (IC-SOHO) comparing olanzapine, quetiapine, risperidone, and haloperidol. J Clin Psychiatry. 2004;65(3):312-321.

17. Gibson PJ, Damler R, Jackson A, Wilder T, Ramsey JL. The impact of olanzapine, risperidone, or haloperidol on the cost of schizophrenia care in a Medicaid population. Value Health. 2004;7(1):22-35.

18. Haro JM, Suarez D, Novick D, et al. Three-year antipsychotic effectiveness in the outpatient care of schizophrenia: observational versus randomized studies results. Eur Neuropsychopharmacol. 2007;17(4):235-244.

19. Jayaram MB, Hosalli PM, Stroup TS. Risperidone versus olanzapine for treatment of schizophrenia. Schizophr Bull. 2007;33(6) 1274-1276.

20. Mudge MAC, Davey PJ, Coleman KA, et al. A comparison of olanzapine versus risperidone for the treatment of schizophrenia: a metaanalysis of randomised clinical trials. Int J Psychiatry Clin Pract. 2005;9(1):3-15.

21. Tunis SL, Faries DE, Nyhuis AW, Kinon BJ, Ascher-Svanum H, Aquila R. Cost-effectiveness of olanzapine as first-line treatment for schizophrenia: results from a randomized, open-label, 1-year trial. Value Health. 2006;9(2):77-89.
22. Williams R, Kopala L, Malla A, Smith G, Love L, Balshaw R. Medication decisions and clinical outcomes in the Canadian National Outcomes Measurement Study in Schizophrenia. Acta Psychiatr Scand Suppl. 2006;113(430):12-21.

23. Eli Lilly and Company. Abbreviated clinical study report: an openlabel study of intramuscular olanzapine depot in patients with schizophrenia or schizoaffective disorder. 2007. Registered at: http://www. ClinicalTrials.gov, July 26, 2004, as NCT00088465 (study code: F1D-MC-HGKB).

24. Ascher-Svanum H, Peng X, Montgomery W, et al. Assessing the infrequent oral supplementation of olanzapine long-acting injection in the treatment of schizophrenia. Eur Psychiatry. 2011;26(5):313-319.

25. McDonnell DP, Andersen SW, Detke HC, Zhao F, Watson SB. Long-term safety and tolerability of open-label olanzapine long-acting injection in the treatment of schizophrenia: 190-week interim results. Clin Med Insights Psychiatry. 2011;2011(3):37-47.

26. Chue P, Llorca PM, Duchesne I, Leal A, Rosillon D, Mehnert A. Hospitalization rates in patients during long-term treatment with longacting risperidone injection. $J$ Appl Res. 2005;5(2):266-274.

27. Fleischhacker WW, Eerdekens M, Karcher K, et al. Treatment of schizophrenia with long-acting injectable risperidone: a 12-month open-label trial of the first long-acting second-generation antipsychotic. J Clin Psychiatry. 2003;64(10):1250-1257.

28. Gharabawi GM, Gearhart NC, Lasser RA, et al. Maintenance therapy with once-monthly administration of long-acting injectable risperidone in patients with schizophrenia or schizoaffective disorder: a pilot study of an extended dosing interval. Ann Gen Psychiatry. 2007;6:3.

29. Kissling W, Heres S, Lloyd K, et al. Direct transition to long-acting risperidone - analysis of long-term efficacy. J Psychopharmacol. 2005;19(Suppl 5):15-21.

30. Lee MS, Ko YH, Lee SH, et al. Long-term treatment with long-acting risperidone in Korean patients with schizophrenia. Hum Psychopharmacol. 2006;21(6):399-407.

31. Lindenmayer JP, Khan A, Eerdekens M, Van Hove I, Kushner S. Long-term safety and tolerability of long-acting injectable risperidone in patients with schizophrenia or schizoaffective disorder. Eur Neuropsychopharmacol. 2007;17(2):138-144.

32. Olivares JM, Rodriguez-Morales A, Diels J, et al. Long-term outcomes in patients with schizophrenia treated with risperidone long-acting injection or oral antipsychotics in Spain: Results from the electronic Schizophrenia Treatment Adherence Registry (e-STAR). Eur Psychiatry. 2009;24(5):287-296.

33. Rossi A, Bagala A, Del Curatolo V, et al. Remission in schizophrenia: one-year Italian prospective study of risperidone long-acting injectable (RLAI) in patients with schizophrenia or schizoaffective disorder. Hum Psychopharmacol. 2009;24(7):574-583.

34. Simpson GM, Mahmoud RA, Lasser RA, et al. A 1-year doubleblind study of 2 doses of long-acting risperidone in stable patients with schizophrenia or schizoaffective disorder. J Clin Psychiatry. 2006;67(8):1194-1203.

35. Lauriello J, Lambert T, Andersen S, Lin D, Taylor CC, McDonnell D. An 8-week double-blind, randomized, placebo-controlled study of olanzapine long-acting injection in acutely ill patients with schizophrenia. J Clin Psychiatry. 2008;69(5):790-799.

36. Eli Lilly and Company. Clinical study report: a double-blind, randomised study comparing intramuscular olanzapine depot to oral olanzapine and low-dose intramuscular olanzapine depot in the maintenance therapy of patients with schizophrenia. 2007. Registered at: http://www.ClinicalTrials.gov, July 26, 2004, as NCT00088491 (study code: F1D-MC-HGKA)

37. Kane JM, Detke HC, Naber D, et al. Olanzapine long-acting injection: a 24-week, randomized, double-blind trial of maintenance treatment in patients with schizophrenia. Am J Psychiatry. 2010;167(2):181-189.

38. Eli Lilly and Company. Clinical pharmacology study report: pharmacokinetic characterization of intramuscular olanzapine depot as a function of particle size distribution. 2005. Registered at: http://www.ClinicalTrials gov, October 21, 2004, as NCT00094640 (study code: F1D-EW-LOBS). 
39. Kane JM, Eerdekens M, Lindenmayer JP, Keith SJ, Lesem M, Karcher $\mathrm{K}$. Long-acting injectable risperidone: efficacy and safety of the first long-acting atypical antipsychotic. Am J Psychiatry. 2003;160(6): 1125-1132.

40. Lindenmayer JP, Eerdekens E, Berry SA, Eerdekens M. Safety and efficacy of long-acting risperidone in schizophrenia: a 12-week, multicenter, open-label study in stable patients switched from typical and atypical oral antipsychotics. J Clin Psychiatry. 2004;65(8):1084-1089.

41. Kay SR, Fiszbein A, Opler LA. The positive and negative syndrome scale (PANSS) for schizophrenia. Schizophr Bull. 1987;13(2):261-276.

42. Leucht S, Kane JM, Kissling W, Hamann J, Etschel E, Engel RR. What does the PANSS mean? Schizophr Res. 2005;79(2-3):231-238.

43. Guy W. ECDEUAssessment Manual for Psychopharmacology, Revised. Publication ADM 76-338. Bethesda, MD: United States Department of Health, Education, and Welfare; 1976.

44. Gaebel W, Riesbeck M, von Wilmsdorff M, et al. Drug attitude as predictor for effectiveness in first-episode schizophrenia: Results of an open randomized trial (EUFEST). Eur Neuropsychopharmacol. 2010;20(5):310-316.

45. Gianfrancesco FD, Rajagopalan K, Sjatovic M, Wang RH. Treatment adherence among patients with schizophrenia treated with atypical and typical antipsychotics. Psychiatry Res. 2006;144(2-3):177-189.

46. Haro JM, Novick D, Suarez D, Roca M. Antipsychotic treatment discontinuation in previously untreated patients with schizophrenia: 36-month results from the SOHO study. J Psychiatr Res. 2009;43(3): 265-273.

47. Hatta K, Sato K, Hamakawa H, et al. Effectiveness of second-generation antipsychotics with acute-phase schizophrenia. Schizophr Res. 2009; 113(1):49-55.
48. Hodgson R, Belgamwar R, al-Tawarah Y, MacKenzie G. The use of atypical antipsychotics in the treatment of schizophrenia in North Staffordshire. Hum Psychopharmacol. 2005;20(2):141-147.

49. Kreyenbuhl J, Slade EP, Medoff DR, et al. Time to discontinuation of first- and second-generation antipsychotic medications in the treatment of schizophrenia. Schizophr Res. 2011;131(1-3):127-132.

50. Tiihonen J, Wahlbeck K, Lönnqvist J, et al. Effectiveness of antipsychotic treatments in a nationwide cohort of patients in community care after first hospitalisation due to schizophrenia and schizoaffective disorder: observational follow-up study. Br Med J. 2006;333(7561):224.

51. Detke HC, Weiden PJ, Llorca PM, et al. Open label comparison of olanzapine long-acting injection and oral olanzapine: a 2-year, randomized study in outpatients with schizophrenia. [Abstract]. Schizophr Bull. 2011;37 Suppl 1:300.

52. Rosenheck RA, Krystal JH, Lew R, et al. Long-acting risperidone and oral antipsychotics in unstable schizophrenia. N Engl J Med. 2011; 364(9):842-851.

53. Chue P, Eerdekens M, Augustyns I, et al. Comparative efficacy and safety of long-acting risperidone and risperidone oral tablets. Eur Neuropsychopharmacol. 2005;15(1):111-117.

54. Emsley R, Oosthuizen P, Koen L, Niehaus DJ, Medori R, Rabinowitz J. Oral versus injectable antipsychotic treatment in early psychosis: post hoc comparison of two studies. Clin Ther. 2008;30(12):2378-2386.

55. Keks NA, Ingham M, Khan A, Karcher K. Long-acting injectable risperidone v. olanzapine tablets for schizophrenia or schizoaffective disorder. Randomised, controlled, open-label study. Br J Psychiatry. 2007;19:131-139.

56. Lambert T, Olivares JM, Peuskens J, et al. Effectiveness of injectable risperidone long-acting therapy for schizophrenia: data from the US, Spain, Australia, and Belgium. Ann Gen Psychiatry. 2011;10:10.
International Journal of General Medicine

\section{Publish your work in this journal}

The International Journal of General Medicine is an international, peer-reviewed open-access journal that focuses on general and internal medicine, pathogenesis, epidemiology, diagnosis, monitoring and treatment protocols. The journal is characterized by the rapid reporting of reviews, original research and clinical studies across all disease areas.

\section{Dovepress}

A key focus is the elucidation of disease processes and management protocols resulting in improved outcomes for the patient.The manuscript management system is completely online and includes a very quick and fair peer-review system. Visit http://www.dovepress.com/ testimonials.php to read real quotes from published authors. 